\title{
Reducing the Burden of Anemia and Neural Tube Defects in Low- and Middle-Income Countries: An Analysis to Identify Countries with an Immediate Potential to Benefit from Large-Scale Mandatory Fortification of Wheat Flour and Rice
}

\author{
Vijaya Kancherla ${ }^{1}$, Manpreet Chadha ${ }^{2, *}$, Laura Rowe ${ }^{3}$, Andrew Thompson ${ }^{2} \mathbb{D}$, Sakshi Jain ${ }^{2}$ (D), Dylan Walters ${ }^{2}$ \\ and Homero Martinez ${ }^{2}$ \\ 1 Center for Spina Bifida Prevention, Department of Epidemiology, Emory University Rollins School of \\ Public Health, Atlanta, GA 30322, USA; vijaya.kancherla@emory.edu \\ 2 Nutrition International, Ottawa, ON K2P 2K3, Canada; athompson@nutritionintl.org (A.T.); \\ sjain@nutritionintl.org (S.J.); dwalters@nutritionintl.org (D.W.); hmartinez@nutritionintl.org (H.M.) \\ 3 Food Fortification Initiative, Atlanta, GA 30322, USA; laura.rowe@ffinetwork.org \\ * Correspondence: mchadha@nutritionintl.org; Tel.: +1-613-859-1452
}

\section{check for} updates

Citation: Kancherla, V.; Chadha, M.; Rowe, L.; Thompson, A.; Jain, S.; Walters, D.; Martinez, H. Reducing the Burden of Anemia and Neural

Tube Defects in Low- and

Middle-Income Countries: An Analysis to Identify Countries with an Immediate Potential to Benefit from Large-Scale Mandatory

Fortification of Wheat Flour and Rice. Nutrients 2021, 13, 244. https:// doi.org/10.3390/nu13010244

Received: 8 December 2020

Accepted: 13 January 2021

Published: 16 January 2021

Publisher's Note: MDPI stays neutral with regard to jurisdictional claims in published maps and institutional affiliations.

Copyright: (C) 2021 by the authors Licensee MDPI, Basel, Switzerland. This article is an open access article distributed under the terms and conditions of the Creative Commons Attribution (CC BY) license (https:/ / creativecommons.org/licenses/by/ $4.0 /)$
Abstract: Using a predetermined set of criteria, including burden of anemia and neural tube defects (NTDs) and an enabling environment for large-scale fortification, this paper identifies 18 low- and middle-income countries with the highest and most immediate potential for large-scale wheat flour and/or rice fortification in terms of health impact and economic benefit. Adequately fortified staples, delivered at estimated coverage rates in these countries, have the potential to avert 72.1 million cases of anemia among non-pregnant women of reproductive age; 51,636 live births associated with folic acid-preventable NTDs (i.e., spina bifida, anencephaly); and 46,378 child deaths associated with NTDs annually. This equates to a $34 \%$ reduction in the number of cases of anemia and $38 \%$ reduction in the number of NTDs in the 18 countries identified. An estimated 5.4 million disability-adjusted life years (DALYs) could be averted annually, and an economic value of 31.8 billion United States dollars (USD) generated from 1 year of fortification at scale in women and children beneficiaries. This paper presents a missed opportunity and warrants an urgent call to action for the countries identified to potentially avert a significant number of preventable birth defects, anemia, and under-five child mortality and move closer to achieving health equity by 2030 for the Sustainable Development Goals.

Keywords: DALYs; fortified foods; developing countries; neural tube defects; anemia; child mortality; infant mortality; women's health; Sustainable Development Goals; health policy

\section{Introduction}

Globally, more than two billion people are not getting the micronutrients (vitamins and minerals) they need to survive and thrive. This includes two of the most critical micronutrients for human development-iron and folate (vitamin B9). Poor diet and limited access to nutrient-rich foods are common reasons for a person's inadequate intake of micronutrients. Insufficient dietary intake of iron leads to iron-deficiency anemia (IDA)the most widespread micronutrient disorder globally affecting nearly 1.6 billion people each year [1,2]. IDA impairs cognitive and motor development, causes fatigue, lowers productivity, and contributes to increased risk of death for a mother and her baby during pregnancy. However, due to limited data at the country level on IDA, anemia was used to estimate potential impact of iron fortification under the assumption that, globally, 50\% of anemia may be caused by IDA, although evidence now suggests that this global figure should be context-specific [1].

Insufficient folate status in the periconceptional period (1-3 months prior to pregnancy and up to the first 28 days after conception) can result in severe and potentially fatal birth 
defects involving the closure of the neural tube, called neural tube defects (NTDs). In 2015, an estimated 260,100 (95\% uncertainty interval: 213,800-322,000) pregnancies were affected by NTDs globally (i.e., approximately 20 cases per 10,000 births), and they largely comprise of spina bifida $(\sim 50 \%)$ and anencephaly $(\sim 38 \%)$, along with encephalocele $(\sim 13 \%)$ to a lesser extent. Of these affected pregnancies, about one in four resulted in elective termination of pregnancy and another one in four in stillbirths; $80 \%$ of the 143,200 live-born infants died before age five [3]. Children surviving with spina bifida face lifelong disabilities and require long-term care [4]. The prevalence of folic acid-preventable NTD cases can be reduced to a lowest achievable level of six cases per 10,000 births by ensuring adequate intake of foods enriched with folic acid (the synthetic form of naturally occurring folate) by women of reproductive age (WRA) during the critical periconceptional window [5].

Staple food enrichment or fortification is a low-cost, high-impact intervention [6] often targeted to medium- and large-scale milling practices and helps address a portion of a population's dietary nutrient gaps and improve health status through the addition of context-specific micronutrient quantities to food staples. Food fortification is one complementary approach to addressing inadequate dietary intake of nutrients such as iron and folate. By adding essential micronutrients to staple foods regularly consumed by populations at large, a significant proportion of adverse health outcomes associated with micronutrient deficiency can be averted [7]. Importantly, this intervention does not require modification to a population's eating habits, nor does it alter the taste, texture, or smell of staple foods; it is generally well accepted by consuming populations [8]. Food fortification is also highly cost-effective as the incremental cost of fortification for consumers is typically within the range of regular market-price fluctuations of up to $2 \%$ [8].

Wheat flour and rice have proven to be ideal vehicles for fortification in many countries due to their widespread coverage and high consumption throughout the year. These staples are also produced in large-scale mills, making them two of the most effective vehicles to deliver nutrients to large segments of the population. Large-scale fortification refers to fortification that happens at industrial, large-scale mills that produce on average $\geq 20$ metric tons of wheat flour or rice per day. In mills of this size, fortification is considered practical and feasible [9]. Mandatory fortification of staple foods, as opposed to voluntary fortification, promotes compliance for domestic production in addition to imported goods, limits the amount of consumer behavior change required, ensures added nutrients can more effectively be measured and monitored, and promotes desirable health impacts due to increased population coverage compared to voluntary policy environments [10]. Mandatory programs have proven to be the most effective means of implementing large-scale fortification programs, as illustrated by a systematic review and meta-analysis of 179 studies, which showed that the total prevalence of spina bifida was 1.5 times lower in countries that had mandatory fortification programs in comparison to that found in countries where fortification was voluntary or had no fortification [11]. Currently, 85 countries around the world mandate the fortification of wheat flour and seven countries mandate the fortification of rice; additionally, 14 countries voluntarily fortify wheat flour and seven countries voluntarily fortify rice [12].

Ending micronutrient malnutrition, thereby addressing the nutritional needs of children, adolescent girls, and women, is an essential component of efforts to ensure countries have equal opportunities for increased productivity, reduced healthcare costs, and life-cycle improvements in health and wellbeing, as well as to achieve a number of the Sustainable Development Goals (SDG), including SDGs 1, 2, 3, 4, 5, 8, 10, 11, and 17 [13].

The objective of this paper is to identify low- and middle-income countries (LMICs) with a high potential for health and human capital impact through implementing large-scale fortification of wheat flour and/or rice with iron and/or folic acid on the basis of best available data as of December 2019. Among identified LMICs, we estimated: (1) country-specific and total prevalence of anemia averted in WRA if countries adopted large-scale fortification of wheat flour and/or rice with recommended levels and forms of iron, (2) country-specific and total number of pregnancies affected with folic acid-preventable NTDs averted if eligible 
countries adopted large-scale fortification of wheat flour and/or rice with recommended levels of folic acid, and (3) the potential economic value of the health benefits of fortification of wheat flour and/or rice with iron and/or folic acid at scale within the eligible LMICs.

\section{Materials and Methods}

Our analysis was initially informed by global and country-specific leaders and partners currently engaged in tracking and promoting large-scale food fortification, with intimate knowledge of national wheat flour and rice fortification efforts and industrial milling opportunities. Country-specific data and information on fortification program status were compiled, vetted, and analyzed by authors collaborating from Nutritional International (NI), the Food Fortification Initiative (FFI), Emory University's Center for Spina Bifida Prevention (CSBP), ReachAnother Foundation, and International Federation for Spina Bifida and Hydrocephalus (IF).

Country selection began with 76 countries suggested by the above collaborating partners on the basis of their knowledge of current fortification efforts in the countries, including appropriate vehicles and current milling infrastructure, political factors, and the presence of an enabling environment from both a public- and a private-sector perspective. Careful consideration was given to these suggestions due to the depth of experience these partners have across programs. Consideration was then given to the prevalence of countryspecific anemia and NTDs and to the degree to which fortification would be a suitable means of addressing the burden in each country. The following criteria were then used to guide the prioritization of countries with the highest impact potential for improving the population's health through mandatory fortification of wheat flour and/or rice with iron and/or folic acid:

(1) Prevalence of anemia among women 15-49 years is $>30 \%$. As per the World Health Organization (WHO) classification [2], a prevalence of anemia over 30\% among WRA indicates a moderate public health problem and a prevalence equal to or over $40 \%$ indicates a severe public health problem [14]. It is worth highlighting that only a few countries have data to differentiate between anemia and IDA. Due to this limitation, we relied on information about anemia prevalence, under the assumption that, globally, $50 \%$ of anemia may be due to IDA [2]. A recent systematic review suggests that this figure may be an overestimate and that actual prevalence of IDA should be assessed in a context-specific manner [1]; and/or.

Prevalence of NTDs is $>6$ per 10,000 births. A recent analysis using blood folate concentrations established that the minimum prevalence of NTDs at optimal blood folate concentrations is six per 10,000 births [5].

(2) Per capita consumption of wheat flour/rice is $\geq 75 \mathrm{~g} / \mathrm{capita} /$ day. According to the WHO, estimated average per capita consumption levels $<75 \mathrm{~g}$ per day do not allow for added micronutrients obtained through a fortification program to meet the nutritional needs of WRA [15]. Country-specific estimates of grain available per capita for consumption were sourced from the Global Fortification Data Exchange (GFDx) website [12]. The data for wheat flour availability includes wheat flour and a variety of wheat-based food products such as pasta, bread, biscuits, and breakfast cereals.

(3) $\geq 75 \%$ of the country's wheat flour/rice is industrially milled. We used data from FFI on the percentage of wheat flour/rice produced in each country that is industrially milled or that is imported from other countries according to responses to an FFI annual survey given to countries [16]. Industrially milled flour that is produced domestically or imported is considered to have the potential for immediate fortification in our analysis.

(4) Optimal fortification design includes status of mandatory fortification or use of appropriate iron and/or folic acid levels and/or compounds. This included countries that were not implementing a mandatory wheat flour/rice fortification program optimally or at all, countries that were implementing a program without iron or folic acid as a fortificant and where the burden of disease indicated a need for the nutrient, or countries implementing programs without iron or folic acid as a fortificant at the recommended level or in the recommended 
form per WHO guidelines [12]. For example, the Philippines has mandatory fortification of both wheat flour and rice but does not include folic acid in the standard. India is another such example where the policy guidance for fortification includes folic acid but at such a low level that it will not make an impact on reducing the prevalence of folic acid-preventable NTDs.

(5) $<50 \%$ of the industrially milled wheat flour/rice is fortified with iron and/or folic acid. Country-specific coverage data for fortification of industrially milled wheat flour/rice was used [12]. Where these data could not be obtained, they were estimated on the basis of partner organization knowledge of the country context. The estimates ensure greater sensitivity in the identification of most countries with immediate fortification potential.

Following the selection of countries based on criteria stated above, and according to the assessed potential of wheat flour/rice fortification at scale in each, we then estimated avertable cases of anemia, folic acid-preventable NTDs, under-five child deaths, disabilityadjusted life years (DALYs), and the economic value of these avertable adverse health outcomes in each country.

\subsection{Estimation Method for Number of Anemia Cases Prevented in Eligible Countries}

Step 1: Quantifying proportion of wheat flour/rice that is industrially milled. The proportion of wheat flour/rice that is industrially milled in a country was estimated by adding the domestic production of industrially milled wheat flour/rice with quantities of grains imported (assumes all imported wheat flour/rice is likely to be industrially milled) and subtracting exported grain, as well as post-harvest and post-processing losses.

Step 2: Quantifying proportion of wheat flour/rice that is industrially milled but not currently fortified. The current percentage of industrially milled wheat flour/rice that is fortified was compared that to the overall proportion of industrially milled wheat flour/rice in the country [12]; the difference represents the amount of wheat flour/rice that is industrially milled with the potential to be fortified.

Step 3: Estimating the total population and total WRA that could be reached by fortified wheat flour/rice (percentage of population consuming the food vehicle). According to readily available per capita consumption data from United Nation's Food and Agricultural Organization (FAO), total production potential estimated in the previous step was divided by countryspecific consumption to quantify the total number of people that could be reached by large-scale fortification; this was stratified for specific demographics including WRA. This information was obtained from national surveys and/or qualitative information from partner organizations currently engaged in promoting food fortification programs in the eligible countries. It was assumed that WRA represent on average approximately $25 \%$ of a country's population, as of 2019 [17].

Step 4: Estimating the number of anemic WRA reached by fortified wheat flour/rice. Countryspecific WRA anemia prevalence estimates were applied to the number of WRA previously estimated (see Step 3) to quantify the number of anemic WRA reached through fortified grains [2].

Step 5: Calculating the number of cases of anemia among WRA that could be averted as a result of large-scale fortification. Documented impact of large-scale food fortification has shown increased serum ferritin in several populations and demonstrated a positive impact on functional outcomes, including a 34\% reduction in anemia (relative risk (RR): 0.66; 95\% confidence interval (CI): 0.59, 0.74) [7]. This effect size was applied to the number of anemic WRA reached through grain fortification to compute the cases of anemia among WRA that could be averted following large-scale fortification in the selected countries.

\subsection{Estimation Method for Number of Folic Acid-Preventable NTDs Prevented and Child Deaths Averted in Eligible Countries: \\ Steps 1 and 2 mentioned in Section 2.1 above were also used to determine the pro- portion of wheat flour/rice that is industrially milled but not currently fortified. The prevalence of folic acid-preventable NTDs in countries with immediate large-scale fortifica- tion potential was then estimated.}


Step 3: Estimating annual number of live births. The annual number of live births per country was obtained from the United Nations database of births for the latest year of data available at the time (2018) [18].

Step 4: Estimating annual number of live births affected by NTDs. Country-specific modeled estimates of the live birth prevalence of NTDs were obtained from the study published by Blencowe et al. (2018) [3]. These estimates are modeled pre-fortification prevalence estimates according to best available data. The country-specific annual number of NTDs was then estimated as the product of 2018 estimated live births taken from the United Nations database of births, and the prevalence of NTDs was taken from Blencowe et al. (2018) estimates. Using Blencowe et al. (2018) estimates, we also estimated the country-specific number of elective terminations and stillbirths with NTDs [3]. To estimate under-five child deaths and survivors to age five, the data from Blencowe et al. (2018) were again used [3].

Step 5: Estimating post-fortification prevalence of NTDs. The post-fortification birth prevalence of NTDs was empirically set at a rate of six per 10,000 births (including live and stillbirths), according to a study by Crider and colleagues (2014) and other published reports from countries with successful folic acid fortification programs that reported a similar NTD prevalence in their post-fortification NTD surveillance studies [19-23].

Step 6: Calculating the annual number of folic acid-preventable NTDs averted per country. On the basis of the estimated coverage of industrially milled rice/wheat flour with the potential to be fortified, the annual number of folic acid-preventable NTD cases averted per country was calculated as the difference in the number of cases according to a country's pre-fortification prevalence number of cases expected post-fortification (i.e., six per 10,000 births). For example, if a country had a NTD prevalence of 25 per 10,000 births (pre-fortification), we first calculated the number of cases that would occur at this prefortification prevalence level, and then subtracted the number of cases that are expected at a post-fortification prevalence of six per 10,000 births.

\subsection{Estimation Method for Number of DALYs Averted and the Economic Value of Health Benefits of Fortification at Scale}

Step 1: Estimating annual number of DALYs averted due to anemia in WRA. The number of years living with disability (YLD) averted, which refers to the total morbidity averted due to anemia, was estimated. This was done by taking the product of the number of cases of anemia averted, the corresponding disability weight of anemia, and the duration of the effect of anemia prevention from consuming adequately fortified staple foods (assumed to be one year only). This calculation used previously derived results for burden of anemia (morbidity) at the country level for each mild, moderate, and severe category of anemia and corresponding disability weights for the matching severity category [24-26].

Step 2: Estimating annual number of DALYs averted due to folic acid-preventable NTDs averted. The years of life lost (YLL), which refers to the total number of years of expected life lost due to premature mortality from folic acid-preventable NTDs, and the number of the number of years living with disability (YLD) averted for children surviving past age five were estimated. The estimation of YLDs averted by averting folic acid-preventable NTDs was estimated as the product of the number of cases of averted NTDs, NTD-specific disability weights, and the expected remaining lifespan of affected children in each country as the duration of the effect of fortification on averting these cases.

The estimation of YLLs averted due to NTDs averted was estimated as the product of the number of cases of folic acid-preventable NTD-related child deaths averted and the expected lifespan of the child in each country. The total number of DALYs averted is the sum of the YLD and YLL averted in each country.

Step 3: Estimating the economic value of health benefits due to fortification at scale. In order to estimate the approximate economic value of the burden of morbidity and mortality averted due to fortification, we undertook a monetized DALY approach using the value of a statistical life $[27,28]$. The estimation of economic value of morbidity and mortality averted due to fortification was estimated as the product of the number of DALYs averted 
and a country-specific value of a statistical life [29]. The resulting figure is an estimate of the potential economic value of health benefits generated by fortification at scale in terms of United States dollars (USD) at the country and aggregate levels. Since averting folic acid-preventable NTDs leads to survival and health benefits that extend far into the future of a child's life, it is important to discount the monetary values of benefits in order to translate them into present value. Discounting of future health and economic impacts is conducted to reflect the opportunity costs of investing in now in nutrition interventions to yield benefits into the future. For the primary analysis in this paper, a commonly used $3 \%$ default discount rate on the number of DALYs averted was used, and alternative $0 \%$ and $5 \%$ discount rates were calculated for the sensitivity analysis [28]. The approximate benefit-cost ratio of global fortification at the aggregate level was estimated using a global unit cost [30].

\section{Results}

The flow diagram shown in Figure 1 summarizes the process via which 18 LMICs with highest and most immediate potential for large-scale fortification of wheat flour and/or rice were identified. Starting with 76 countries recommended by the collaborating partners, six countries were excluded due to their high-income status, 37 were excluded when the quantitative criteria were applied, one country was excluded due to a perceived degree of political instability, and five were further excluded when the qualitative criteria were applied. This resulted in 18 priority countries of interest. Table 1 shows the 18 countries thus identified, namely, Angola, Bangladesh, Benin, China, Côte d'Ivoire, Egypt, Ethiopia, Ghana, India (17 states), Indonesia, Kazakhstan, Kyrgyzstan, Liberia, Morocco, Nigeria, Philippines, Senegal, and Tanzania. An additional nine countries were also shortlisted but were not further assessed for impact due to their small population size ( $<3$ million people), additional contextual knowledge pertaining to political barriers, or uncertainty about existing fortification efforts. Table 1 summarizes the prevalence of anemia among WRA, NTD prevalence, per capita consumption of selected grains, and percentage availability of industrially milled cereal in each eligible country. Results for 17 Indian states are presented separately (Table A1), in view of their large population size, state regulations independent of a national regulation, and extent of social protection programs. A more detailed, qualitative analysis of country-specific reasons for selecting these 18 countries is presented in Table 2.

For wheat flour fortification, 12 LMICs were identified with an immediate potential for large-scale fortification with iron and/or folic acid. Of these countries, three have voluntary fortification (China, Ethiopia, and India), three do not have a mandate to fortify wheat flour with folic acid and/or iron (Angola, Bangladesh, and Egypt), three have legislation to mandate fortification of wheat flour with iron and/or folic acid but fortify less than $50 \%$ of industrially milled wheat flour (Kazakhstan, Kyrgyzstan, and Tajikistan), and three have a legislation to mandate but do not use iron and/or folic acid as a fortificant, do not use iron and/or folic acid in the globally recommended amounts, or do not use iron and/or folic acid in the globally recommended fortificant forms (Indonesia, Morocco, and Philippines) (Table 3). For rice fortification, nine LMICs were identified that have a high and immediate potential for fortification with iron and/or folic acid. Three of the nine LMICs identified also have a wheat flour fortification program. Of the nine countries, seven do not have a mandate to fortify rice with iron and/or folic acid (Benin, China, Côte d'Ivoire, Ghana, Liberia, Nigeria, and Senegal) and two voluntarily fortify rice (Bangladesh and India) (Table 4).

In these 12 countries identified for wheat flour fortification, a total of 133.1 million metric tons of wheat flour is available for fortification, of which 7.1 million metric tons is fortified, and an additional 125.9 million metric tons of wheat flour can be fortified (Table 5). In the nine countries identified for rice fortification, a total of 141.3 million metric tons of rice was available for fortification, of which about 0.015 million metric tons was being fortified, and an additional 141.2 million metric tons of rice can be fortified (Table 5). 


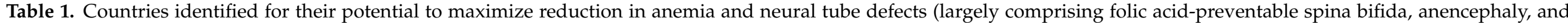
encephalocele) through large-scale fortification of wheat flour/rice with iron and/or folic acid.

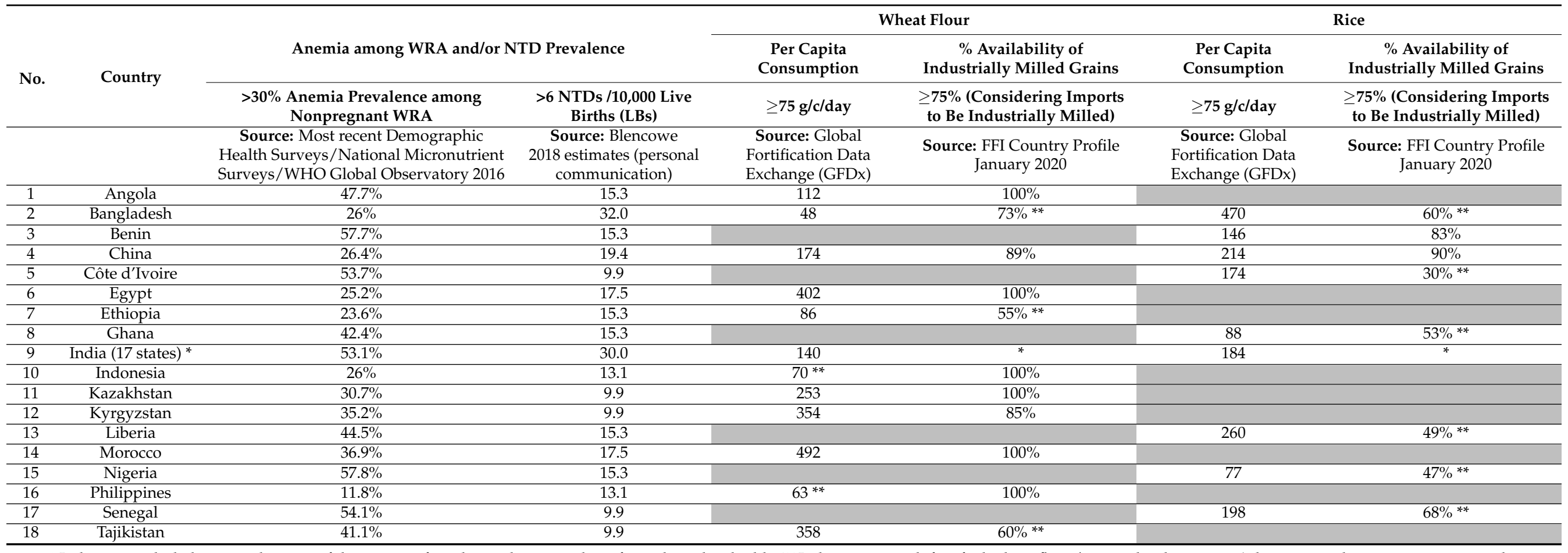

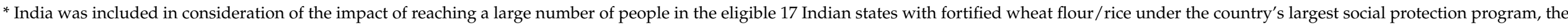

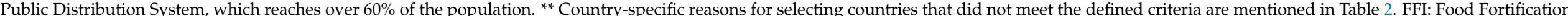

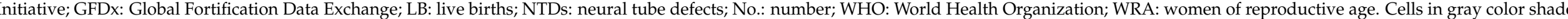
indicate that these countries were not selected for fortification of given food vehicle. 
Table 2. Country-specific reasons for selecting 18 low- and middle-income countries with high potential for large-scale fortification of wheat flour/rice.

\begin{tabular}{|c|c|}
\hline \multicolumn{2}{|c|}{ A. Strong political will and/or reach opportunity } \\
\hline Bangladesh and India & $\begin{array}{l}\text { The governments of Bangladesh and India have demonstrated strong political will for fortification through the adoption of voluntary } \\
\text { fortification of wheat flour and rice, and the countries are committed to the integration of these fortified vehicles into national social } \\
\text { safety net programs. This presents an immediate opportunity to reach the most vulnerable populations at scale. India has the largest } \\
\text { number of pregnancies in the world affected by NTDs and presents an opportunity to reach } 400 \text { million people with fortified wheat } \\
\text { flour/rice. }\end{array}$ \\
\hline China & $\begin{array}{l}330,000 \text { pregnancies are affected by NTDs each year; this is } 13 \% \text { of the global total and second only to India in the number of pregnancies } \\
\text { affected [3]. With such a significant burden, there is high potential in China to prevent NTDs through folic acid fortification. }\end{array}$ \\
\hline Egypt & $\begin{array}{l}\text { Egypt is yet another case exhibiting strong political support and potential for expansive reach. The government is currently working to } \\
\text { restart the country's social safety net wheat flour fortification program with interest in expanding it into the open market. Fortified } \\
\text { wheat flour provided through the social safety net program alone would reach over } 73 \text { million vulnerable people. If fortified wheat flour } \\
\text { was provided through both the social safety net program and the open market, } 90 \% \text { of the population would be reached (Food } \\
\text { Fortification Initiative, personal communication). }\end{array}$ \\
\hline Ethiopia & $\begin{array}{l}\text { Although only } 55 \% \text { of Ethiopia's wheat flour is milled industrially and the coverage of fortifiable wheat flour in Ethiopia is only } \\
28 \% \text { [31], this country was included due to the relatively large population of Ethiopia ( } 104.9 \text { million) and high rate of NTDs } \\
\text { (130 per 10,000 births) [32]. Coverage of only } 28 \% \text { in this country means that almost } 30 \text { million people can be reached with fortified foods. } \\
\text { Additionally, the government has adopted voluntary fortification of wheat flour, exhibiting strong political will to address micronutrient } \\
\text { deficiencies through fortification. Lastly, there are multiple champions to support fortification of wheat flour with folic acid in the } \\
\text { country. }\end{array}$ \\
\hline \multicolumn{2}{|c|}{ B. Opportunity for fortifying imports } \\
\hline $\begin{array}{l}\text { Angola } \\
\text { Bangladesh } \\
\text { Benin } \\
\text { Côte d'Ivoire } \\
\text { Ghana } \\
\text { Indonesia } \\
\text { Liberia } \\
\text { Philippines } \\
\text { Senegal }\end{array}$ & $\begin{array}{l}\text { Imported wheat flour and/or rice remain a dominant staple, presenting an opportunity for feasible and effective grain fortification in } \\
\text { half of the eligible countries ( } 9 \text { out of } 18) \text {. By mandating fortification of imported wheat flour/rice, these countries could reap large } \\
\text { public health benefits while facilitating an enabling environment for other countries in the region seeking similar mandates. A } \\
\text { considerable proportion of wheat flour that is available for consumption is imported in Angola }(>90 \%) \text {, Philippines, }(>90 \%) \text {, Indonesia } \\
(>90 \%) \text {, and Bangladesh }(>70 \%) \text {. The same holds true for rice in Benin }(>90 \%) \text {, Senegal }(>70 \%) \text {, Côte d'Ivoire }(>50 \%) \text {, Ghana }(>50 \%) \text {, and } \\
\text { Liberia }(>50 \%) \text {. }\end{array}$ \\
\hline Nigeria & $\begin{array}{l}\text { Nigeria consumes more rice than any other country in Africa and, although only } \sim 37 \% \text { of the rice available for consumption is } \\
\text { imported [16], the large population (190.8 million), high burden of anemia among women of reproductive age }(47 \%) \text {, and high } \\
\text { prevalence of neural tube defects }(15 / 10,000 \text { live births) make it a tremendous opportunity for rice fortification. }\end{array}$ \\
\hline
\end{tabular}


Table 2. Cont.

\section{Support required due to technical limitations and constrained resources (market, economic, and behavior)}

Kazakhstan, Kyrgyzstan, Morocco, Philippines, and Tajikistan have all expressed strong political will by legislating fortification of wheat flour. While Tajikistan is the newest country to legislate wheat flour fortification in 2018 and would benefit from support, suboptimal implementation of the legislation in Kazakhstan, Kyrgyzstan, Morocco, and the Philippines is hindering the achievement of optimal

KazakhstanKyrgyzstanMoroccoPhilippinesTajikistan

health impact in these countries. Support for the industry to adequately fortify wheat flour and for the government to enforce

monitoring and compliance to the national fortification standards in these countries will go a long way in ensuring a sustainable wheat flour fortification intervention. In the Philippines, simply adding folic acid to the already-existing wheat flour/rice fortification

standards and enforcing its implementation will help the country address the high burden of NTDs. 


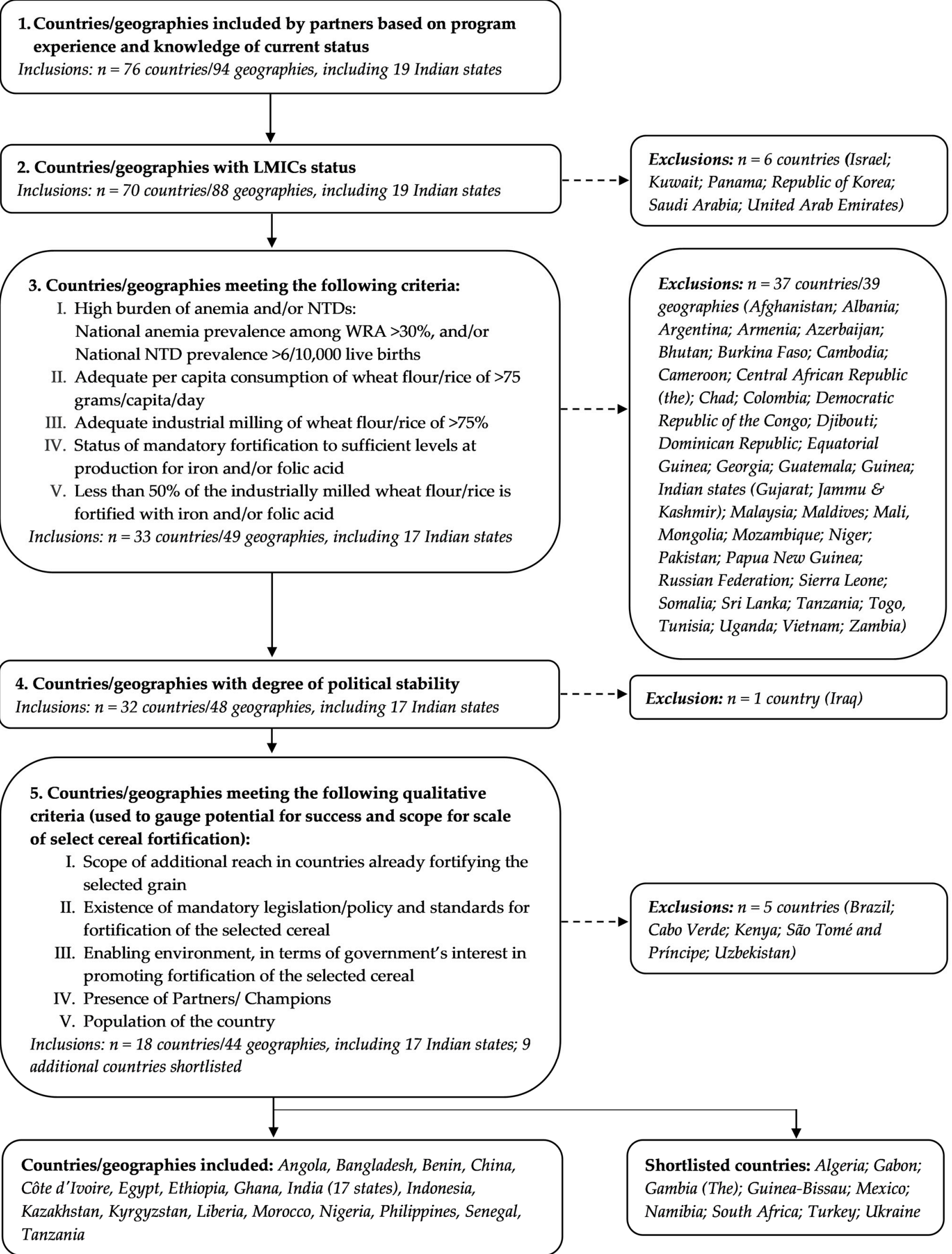

Figure 1. Flow diagram shows selection process to identify eligible countries with high impact potential for large-scale food fortification of wheat flour or rice. 


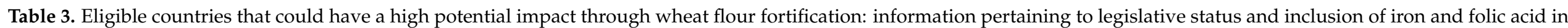
fortification standards.

\begin{tabular}{|c|c|c|c|c|c|c|c|}
\hline \multirow[b]{3}{*}{ No. } & \multirow[b]{3}{*}{ Eligible Country } & \multicolumn{6}{|c|}{ Wheat Flour Fortification } \\
\hline & & \multirow[b]{2}{*}{ Legislation } & \multicolumn{3}{|c|}{ Iron } & \multicolumn{2}{|c|}{ Folic Acid (ppm) } \\
\hline & & & Level (ppm) & $\begin{array}{l}\text { Compound } \\
\text { Indicated in } \\
\text { Standard }\end{array}$ & $\begin{array}{l}\text { Level (ppm) as Per Global } \\
\text { Recommendation for Country's } \\
\text { Cereal Grain Consumption }\end{array}$ & Level (ppm) & $\begin{array}{l}\text { Level (ppm) as Per Global } \\
\text { Recommendation for Country's } \\
\text { Cereal Grain Consumption }\end{array}$ \\
\hline 1 & Angola * & Unknown & \multicolumn{2}{|c|}{ No fortification standard } & $\begin{array}{c}40 \text { as NaFeEDTA *** } \\
60 \text { as FF/FS **** }\end{array}$ & $\begin{array}{l}\text { No fortification } \\
\text { standard }\end{array}$ & 2.6 \\
\hline 2 & Bangladesh ** & Unknown & 55 & Not specified & $\begin{array}{c}40 \text { as NaFeEDTA } \\
60 \text { as FF/FS } \\
* * * *\end{array}$ & 2 & 5 \\
\hline 3 & China * & Voluntary 2012 & 20 & No information & $\begin{array}{l}20 \text { as NaFeEDTA } \text { A }^{* * *} \\
30 \text { as FF/FS } \\
60 \text { as EI }{ }^{* * * *}\end{array}$ & 2 & 1.3 \\
\hline 4 & Egypt* & Unknown & \multicolumn{2}{|c|}{ No fortification standard } & $\begin{array}{c}15 \text { as NaFeEDTA } \\
20 \text { as FF/FS } \\
40 \text { as EI } \\
\text { ******}\end{array}$ & $\begin{array}{l}\text { No fortification } \\
\text { standard }\end{array}$ & 1 \\
\hline 5 & Ethiopia ** & Voluntary 2017 & $\begin{array}{l}30 \\
40\end{array}$ & $\begin{array}{l}\text { NaFeEDTA } * * * \\
\text { FF }^{* * *}\end{array}$ & $\begin{array}{l}40 \text { as NaFeEDTA *** } \\
60 \text { as FF/FS *** }\end{array}$ & 2 & 2.6 \\
\hline 6 & India (6 states) ${ }^{* * \#}$ & Voluntary 2018 & $\begin{array}{c}14-21.25 \\
28-42.5\end{array}$ & $\begin{array}{l}\text { NaFeEDTA }{ }^{* * *} \\
\text { FS/FF/EI/FC/FP/FB/FL } \\
* * *\end{array}$ & 20 as NaFeEDTA *** & $0.075-0.125$ & 1.3 \\
\hline 7 & Indonesia ** & Mandatory 2001 & 50 & $\underset{* * *}{\mathrm{NaFeEDTA} / \mathrm{FF} / \mathrm{FS}}$ & $\begin{array}{l}40 \text { as NaFeEDTA *** } \\
\quad 60 \text { as FF/FS *** }\end{array}$ & 2 & 5 \\
\hline 8 & Kazakhstan * & Mandatory 2005 & 55 & - & $\begin{array}{l}20 \text { as NaFeEDTA } \text { A }^{* * *} \\
30 \text { as FF/FS ***} \\
60 \text { as EI }{ }^{* * *}\end{array}$ & 1.4 & 1.3 \\
\hline 9 & Kyrgyzstan * & Mandatory 2009 & No forti & on standard & $\begin{array}{c}15 \text { as NaFeEDTA } * * * \\
20 \text { as FF/FS } * * * \\
40 \text { as EI }{ }^{* * *}\end{array}$ & $\begin{array}{l}\text { No fortification } \\
\text { standard }\end{array}$ & 1 \\
\hline
\end{tabular}


Table 3. Cont

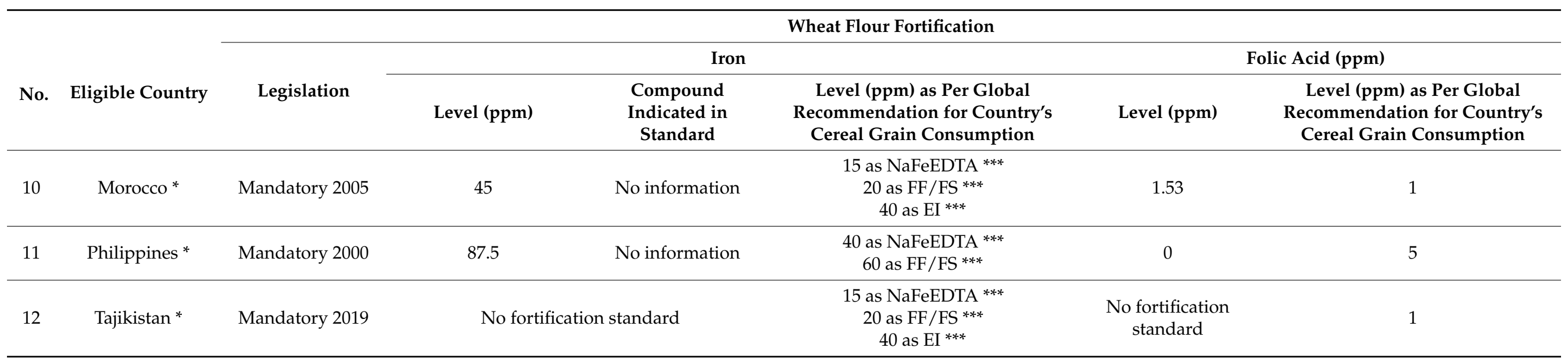

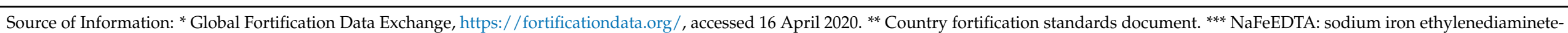

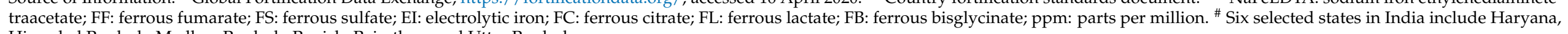
Himachal Pradesh, Madhya Pradesh, Punjab, Rajasthan, and Uttar Pradesh. 


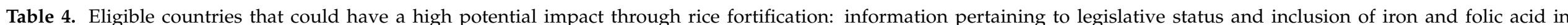
fortification standards.

\begin{tabular}{|c|c|c|c|c|c|c|c|}
\hline \multirow[b]{3}{*}{ No. } & \multirow[b]{3}{*}{ Eligible Country } & \multicolumn{6}{|c|}{ Rice Fortification } \\
\hline & & \multirow[b]{2}{*}{ Legislation } & \multicolumn{3}{|c|}{ Iron } & \multicolumn{2}{|c|}{ Folic Acid (ppm) } \\
\hline & & & Level (ppm) & $\begin{array}{l}\text { Compound } \\
\text { Indicated in } \\
\text { Standard }\end{array}$ & $\begin{array}{l}\text { Level (ppm) as Per Global } \\
\text { Recommendation for } \\
\text { Country's Cereal Grain } \\
\text { Consumption }\end{array}$ & Level (ppm) & $\begin{array}{c}\text { Level (ppm) as Per Global } \\
\text { Recommendation for } \\
\text { Country's Cereal Grain } \\
\text { Consumption }\end{array}$ \\
\hline 1 & Bangladesh ** & Voluntary 2015 & 60 & $\begin{array}{l}\text { Micronized ferric } \\
\text { pyrophosphate }\end{array}$ & $\begin{array}{c}70 \text { as micronized ferric } \\
\text { pyrophosphate }\end{array}$ & 1.7 & 1 \\
\hline 3 & China * & None & \multicolumn{2}{|c|}{ No fortification standard } & $\begin{array}{l}70 \text { as micronized ferric } \\
\text { pyrophosphate }\end{array}$ & $\begin{array}{l}\text { No fortification } \\
\text { standard }\end{array}$ & 1.3 \\
\hline 4 & Côte d'Ivoire & None & \multicolumn{2}{|c|}{ No fortification standard } & $\begin{array}{l}70 \text { as micronized ferric } \\
\text { pyrophosphate }\end{array}$ & $\begin{array}{l}\text { No fortification } \\
\text { standard }\end{array}$ & 1.3 \\
\hline 5 & Ghana * & None & \multicolumn{2}{|c|}{ No fortification standard } & $\begin{array}{l}120 \text { as micronized ferric } \\
\text { pyrophosphate }\end{array}$ & $\begin{array}{l}\text { No fortification } \\
\text { standard }\end{array}$ & 2.6 \\
\hline 7 & Liberia * & None & \multicolumn{2}{|c|}{ No fortification standard } & $\begin{array}{l}70 \text { as micronized ferric } \\
\text { pyrophosphate }\end{array}$ & $\begin{array}{l}\text { No fortification } \\
\text { standard }\end{array}$ & 1.3 \\
\hline 8 & Nigeria * & None & \multicolumn{2}{|c|}{ No fortification standard } & $\begin{array}{l}120 \text { as micronized ferric } \\
\text { pyrophosphate }\end{array}$ & $\begin{array}{l}\text { No fortification } \\
\text { standard }\end{array}$ & 2.6 \\
\hline 9 & Senegal ** & None & \multicolumn{2}{|c|}{ No fortification standard } & $\begin{array}{l}70 \text { as micronized ferric } \\
\text { pyrophosphate }\end{array}$ & $\begin{array}{l}\text { No fortification } \\
\text { standard }\end{array}$ & 1.3 \\
\hline
\end{tabular}

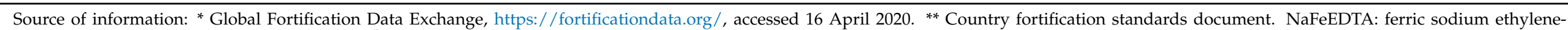

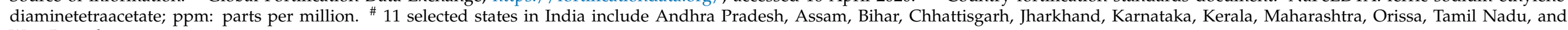
West Bengal. 
Table 5. Proportion and amount of industrially milled wheat flour and rice available for fortification in each eligible country.

\begin{tabular}{|c|c|c|c|c|c|c|c|c|c|c|c|c|c|}
\hline \multirow[b]{2}{*}{ No. } & \multirow[b]{2}{*}{$\begin{array}{l}\text { Eligible } \\
\text { Country }\end{array}$} & \multicolumn{8}{|c|}{ Wheat Flour } & \multicolumn{4}{|c|}{ Rice } \\
\hline & & $\begin{array}{c}\text { Proportion of } \\
\text { Industrially } \\
\text { Milled Wheat } \\
\text { Flour Available } \\
\text { Post Har- } \\
\text { vest/Processing } \\
\text { Available for } \\
\text { consumption } \\
\text { (\%)-To } \\
\text { Achieve Scale }\end{array}$ & $\begin{array}{c}\text { Total } \\
\text { Industrially } \\
\text { Milled Wheat } \\
\text { Flour Available } \\
\text { Post Harvest/ } \\
\text { Processing } \\
\text { Available for } \\
\text { Consumption } \\
\text { (MT) }\end{array}$ & $\begin{array}{l}\text { Proportion of } \\
\text { Industrially } \\
\text { Milled Wheat } \\
\text { Flour Available } \\
\text { That Is Already } \\
\text { Fortified (\%) }\end{array}$ & $\begin{array}{c}\text { Total } \\
\text { Industrially } \\
\text { Milled Wheat } \\
\text { Flour Available } \\
\text { That Is Already } \\
\text { Fortified (MT) }\end{array}$ & $\begin{array}{c}\text { Proportion of } \\
\text { Industrially } \\
\text { Milled Wheat } \\
\text { Flour Available } \\
\text { with Potential } \\
\text { to be Fortified } \\
(\%)\end{array}$ & $\begin{array}{c}\text { Total } \\
\text { Industrially } \\
\text { Milled Wheat } \\
\text { Flour Available } \\
\text { with Potential } \\
\text { to be Fortified } \\
\text { (MT) }\end{array}$ & $\begin{array}{c}\text { Proportion of } \\
\text { Industrially } \\
\text { Milled Rice } \\
\text { Available Post } \\
\text { Harvest/ } \\
\text { Processing } \\
\text { Available for } \\
\text { Consumption } \\
\text { (\%)-To } \\
\text { Achieve Scale }\end{array}$ & $\begin{array}{c}\text { Total } \\
\text { Industrially } \\
\text { Milled Rice } \\
\text { Available Post } \\
\text { Harvest// } \\
\text { Processing } \\
\text { Available for } \\
\text { Consumption } \\
\text { (MT) }\end{array}$ & $\begin{array}{l}\text { Proportion of } \\
\text { Industrially } \\
\text { Milled rice } \\
\text { Available That } \\
\text { Is Already } \\
\text { Fortified (\%) }\end{array}$ & $\begin{array}{c}\text { Total } \\
\text { Industrially } \\
\text { Milled Rice } \\
\text { Available That } \\
\text { Is Already } \\
\text { Fortified (MT) }\end{array}$ & $\begin{array}{l}\text { Proportion of } \\
\text { Industrially } \\
\text { Milled Rice } \\
\text { Available with } \\
\text { Potential to be } \\
\text { Fortified (\%) }\end{array}$ & $\begin{array}{c}\text { Total } \\
\text { Industrially } \\
\text { Milled Rice } \\
\text { Available with } \\
\text { Potential to be } \\
\text { Fortified (MT) }\end{array}$ \\
\hline 1 & Angola & $70 \%$ & 368,972 & $0 \%$ & - & $70 \%$ & 368,972 & & & & & & \\
\hline 3 & Benin & & & & & & & $97 \%$ & $1,374,002$ & $0 \%$ & - & $97 \%$ & $1,374,002$ \\
\hline 4 & China & $63 \%$ & $80,697,739$ & $1 \%$ & 806,977 & $62 \%$ & $79,890,761$ & $90 \%$ & $113,060,636$ & $0 \%$ & - & $90 \%$ & $113,060,636$ \\
\hline 5 & Côte d'Ivoire & & & & & & & $40 \%$ & 779,045 & $0 \%$ & - & $40 \%$ & 779,045 \\
\hline 6 & Egypt & $70 \%$ & $13,782,824$ & $0 \%$ & - & $70 \%$ & $13,782,824$ & & & & & & \\
\hline 7 & Ethiopia & $48 \%$ & $2,654,994$ & $0 \%$ & - & $48 \%$ & $2,654,994$ & & & & & & \\
\hline 8 & Ghana & & & & & & & $65 \%$ & 644,328 & $0 \%$ & - & $65 \%$ & 644,328 \\
\hline 9 & $\begin{array}{l}\text { India (17 } \\
\text { states) }\end{array}$ & * & $12,853,149$ & $0 \%$ & - & * & $12,853,149$ & $*$ & $20,330,033$ & $0 \%$ & - & * & $20,330,033$ \\
\hline 10 & Indonesia & $70 \%$ & $4,813,060$ & $61 \%$ & $4,187,362$ & $9 \%$ & 625,698 & & & & & & \\
\hline 11 & Kazakhstan & $70 \%$ & $4,943,239$ & $29 \%$ & $\frac{1,026,728}{2,028}$ & $41 \%$ & $2,916,511$ & & & & & & \\
\hline 12 & Kyrgyzstan & $63 \%$ & 838,878 & $4 \%$ & 58,721 & $59 \%$ & 780,157 & & & & & & \\
\hline 13 & Liberia & & & & & & & $62 \%$ & 264,208 & $0 \%$ & - & $62 \%$ & 264,208 \\
\hline 15 & Nigeria & & & & & & & $54 \%$ & $3,076,626$ & $0 \%$ & - & $54 \%$ & $3,076,626$ \\
\hline 16 & Philippines & $70 \%$ & $1,857,509$ & $0 \%$ & - & $70 \%$ & $1,857,509$ & & & & & & \\
\hline 17 & Senegal & & & & & & & $80 \%$ & $1,035,376$ & $0 \%$ & - & $80 \%$ & $1,035,376$ \\
\hline 18 & Tajikistan & $56 \%$ & $1,023,695$ & $0 \%$ & - & $56 \%$ & $1,023,695$ & & & & & & \\
\hline & Total & & $133,050,662$ & & $7,105,387$ & & $125,945,275$ & & $141,314,254$ & & 15,000 & & $141,299,254$ \\
\hline
\end{tabular}

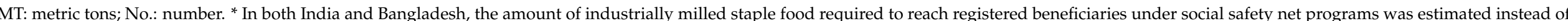

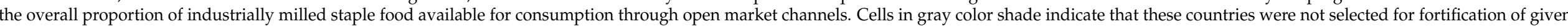
food vehicle. 


\subsection{Number of Cases of Anemia Prevented among WRA}

By fortifying industrially milled wheat flour and/or rice with iron in the 18 countries identified in the analysis, 72.1 million new cases of anemia among WRA could be averted annually (Tables 6 and A1). That equates to an 11.8\% reduction in the number of cases of anemia globally, and a $34.2 \%$ reduction of the burden of anemia in the 18 countries analyzed.

Table 6. Estimated annual health and economic benefits of fortification at scale in countries of interest.

\begin{tabular}{|c|c|c|c|c|c|c|}
\hline Country & $\begin{array}{c}\text { Number of } \\
\text { People Reached } \\
\text { (Millions) }\end{array}$ & $\begin{array}{c}\text { Cases of } \\
\text { Anemia in } \\
\text { WRA Averted }\end{array}$ & $\begin{array}{l}\text { Cases of } \\
\text { NTDs } \\
\text { Averted }\end{array}$ & $\begin{array}{l}\text { Child Deaths } \\
\text { Averted }\end{array}$ & $\begin{array}{c}\text { DALYs } \\
\text { Averted }\end{array}$ & $\begin{array}{c}\text { Economic Value of } \\
\text { DALYs Averted } \\
\text { (in Millions of USD) }\end{array}$ \\
\hline Angola & 9.0 & 365,698 & 816 & 769 & 57,522 & 383 \\
\hline Bangladesh & 144.6 & $3,194,605$ & 4154 & 3857 & 369,392 & 594 \\
\hline Benin & 10.3 & 503,202 & 375 & 354 & 38,998 & 64 \\
\hline China & 1284.8 & $28,831,810$ & 14,037 & 11,681 & $1,701,396$ & 20,298 \\
\hline Côte d'Ivoire & 12.3 & 559,521 & 142 & 134 & 26,294 & 93 \\
\hline Egypt & 88.6 & $1,896,955$ & 2077 & 1783 & 161,352 & 699 \\
\hline Ethiopia & 84.5 & $1,695,531$ & 1397 & 1315 & 140,088 & 141 \\
\hline Ghana & 20.0 & 722,468 & 531 & 499 & 54,008 & 147 \\
\hline $\begin{array}{l}\text { India (17 } \\
\text { states) }\end{array}$ & 553.1 & $24,950,107$ & 22,006 & 20,410 & $2,198,103$ & 5532 \\
\hline Indonesia & 24.5 & 540,840 & 312 & 274 & 35,071 & 196 \\
\hline Kazakhstan & 16.5 & 429,785 & 62 & 53 & 16,768 & 370 \\
\hline Kyrgyzstan & 5.7 & 169,646 & 36 & 29 & 7666 & 17 \\
\hline Liberia & 2.8 & 105,235 & 92 & 87 & 8555 & 6 \\
\hline Morocco & 32.4 & $1,016,226$ & 547 & 454 & 66,193 & 310 \\
\hline Nigeria & 109.4 & $5,374,530$ & 3731 & 3519 & 362,564 & 2364 \\
\hline Philippines & 80.7 & 809,657 & 1089 & 954 & 102,517 & 537 \\
\hline Senegal & 14.2 & 653,907 & 171 & 161 & 32,183 & 64 \\
\hline Tajikistan & 7.8 & 273,501 & 61 & 47 & 11,371 & 29 \\
\hline Total & $2.5 \mathrm{~B}$ & $72.1 \mathrm{M}$ & 51,636 & 46,378 & $5.4 \mathrm{M}$ & $31.84 \mathrm{~B}$ \\
\hline
\end{tabular}

DALYs: disability adjusted life years; NTDs: neural tube defects; USD: United States dollar; WRA: women of reproductive age; B: billion; M: million.

\subsection{Number of Cases of NTD Prevented and Under-Five Deaths Averted}

By fortifying the industrially milled wheat flour and/or rice with folic acid in countries of interest, 51,636 new cases of folic acid-preventable NTDs could be averted (Tables 6 and A1). That equates to a $38 \%$ reduction in the countries of interest. Additionally, 46,378 under-five child deaths associated with NTDs could be averted annually by fortification at scale.

\subsection{Value of Morbidity and Mortality Averted}

The health and human capital impacts on the countries of interest are presented in Table 6. As a result of the estimated health impact of fortification at scale, there is the potential to avert 2.16 million YLD due to anemia prevented, 14,750 YLD due to folic acid-preventable NTDs averted, and 3.22 million YLL due to these averted cases. In aggregate, fortification has the potential to avert 5.4 million DALYs annually and generate an estimated economic value of 31.8 billion USD over the lifespan of women and children beneficiaries (Tables 6, A2 and A3). A disproportionate amount of the total discounted economic value benefits China (63\%), due to its high value of a statistical life and large population, and $64 \%$ of the aggregate economic value is associated with the prevention 
of anemia in women (at a 3\% discount rate). Using an approximate global fortification unit cost of 0.37 USD per person reached, this translates into a mean benefit-cost ratio of 34:1 USD (range = 4-115:1 USD, median 20:1 USD) (Tables A4 and A5) [32]. Even when doubling or tripling the unit cost per person reached in a sensitivity analysis (given variation in unit costs across countries and type of staple food), the mean benefit-cost ratio remains positive and high.

\section{Discussion}

This analysis, conducted by a consortium of international experts and organizations, used the best available country-level data on the burden of anemia and NTDs, current fortification status, existing industrial milling opportunity, and amount of daily per capita wheat flour and/or rice available for human consumption to provide a comprehensive assessment of fortification potential in each country.

Eighteen LMICs were identified with the greatest potential for preventing anemia, folic acid-preventable NTDs, and associated under-five child deaths by implementing large-scale, mandatory fortification of wheat flour and/or rice with iron and folic acid. If implemented effectively and at scale across all 18 countries selected, 72.1 million cases of anemia among WRA, 51,636 cases of folic acid-preventable NTDs, and 46,378 child deaths among those born with NTDs could be averted. While the total numbers of potential cases of anemia and NTDs averted are highest in large countries such as China, there is a much higher potential for cases averted per capita in countries with a higher prevalence of anemia (i.e., Nigeria, Benin, Côte d'Ivoire, and India) or folic acid-preventable NTDs (i.e., Angola, India, Benin, and Nigeria). This magnitude and type of prevention has lifelong health and economic implications and would make a significant contribution to reaching the health and equity 2030 SDGs. This study estimated that fortification at scale has an economic value of 31.8 billion USD per year and yields a positive benefit-cost ratio (with expected variation between countries) that is consistent with previous cost-benefit analyses in the literature $[33,34]$. This analysis did not estimate the benefit of preventing folate deficiency anemia; therefore, the health and economic benefits could be considered conservative. Detailed, country-level health and economic evaluation is recommended.

Large-scale food fortification conveys equitable benefits across populations that consume fortifiable food grains. Fortification is proven to be one of the most successful and cost-effective public health programs that countries can invest in, using minimal resources and funds [35]. Furthermore, the benefits of fortification compound annually as anemia, NTDs, and associated morbidity and mortality are averted each year. Once industrial mills begin fortification as part of standard operating procedures, the same technology can be used to include other vitamins and minerals (e.g., zinc, vitamin $B_{12}$, and other B vitamins) and address multiple nutritional deficiencies without substantial additional expenses.

This review purposely chose food staples such as wheat flour and rice that are regularly and widely consumed by a large portion of population groups in respective countries to allow prioritization as a function of maximum reach and impact potential. It further sought to ensure that all segments of the population will benefit from fortified foods due to the low cost required to add micronutrients. This is particularly the case for urban slum areas and through social safety nets where centrally processed fortified foods reach the poorest and most vulnerable.

Barriers to the implementation of successful, large-scale mandatory food fortification programs have been documented and can be multi-faceted, including political instability, lack of political support leading to under-prioritization of fortification by the government, absence of incentives for food industry, food industry's lack of capacity and resources, and ineffective and weak regulation and enforcement [36]. Efforts required to overcome important hurdles and achieve long-term success include more effective communication around the cost savings (human and financial) of fortification at the country level and shifts in political commitment for initiating and sustaining a program. Furthermore, it is recommended that stakeholders assess barriers by conducting a thorough landscape 
assessment of enabling and disabling factors including the presence (or absence) of champions in-country who could drive a fortification agenda and promote sustained government commitment [37]. The proposed countries in our review were given careful consideration to these factors to ensure a high potential for success.

Although the 18 countries identified in this study are those that were found to have the most immediate impact on prevention of anemia among WRA and NTDs, this does not mean that the excluded countries, including those that are high-income and those that have a degree of political instability, would not also benefit from strong and sustained technical support. Socio-economic and health disparities within high-income countries should not be discounted. Although the authors chose a country's income status as a criterion, another approach could have been to stay agnostic to income status while highlighting the preventable health disparities within and between countries, particularly in light of the number of high-income countries that fail to mandate fortification. Additionally, the 76 countries with which the analysis started were based on collaborating partners' subjective, expert recommendations gleaned from years of sustained efforts with government counterparts and industry in the countries analyzed. In the future, a comprehensive global analysis would allow for a more detailed comparison between this paper's included and excluded countries. Our prevention estimates for anemia and folic acid-preventable NTDs may be conservative as they are aggregated across multiple settings and derived from modeled extrapolations. Therefore, actual impact could be higher than estimated. While estimating impact of food fortification on anemia, benefits reaching non-WRA were not calculated. Similarly, prevention of folic acid-preventable NTDs among early spontaneous abortions could not be estimated.

Despite its limitations, this analysis has several strengths. It is timely, relevant, and actionable. The analysis used best available data and prevalence estimates for modeling health impact as a result of scaling up wheat flour and rice fortification programs. The analysis was compiled by leaders in the fields of nutrition, food fortification, and epidemiology of NTDs who collaborated to present this comprehensive review of fortification in select countries. Factors included in this prioritization exercise are established, industry-relevant criteria for fortification at scale.

\section{Conclusions}

Effective fortification programs are needed in countries that demonstrate high rates of anemia among WRA due to iron deficiency and high occurrence of NTDs due to maternal folate deficiency before and during early pregnancy.

Where there is a demonstrated need and appropriate food vehicle(s) for effective delivery of key micronutrients, much progress has been made globally to ensure national mandatory fortification programs are put in place. However, there are still many countries that could benefit from the health and economic gains of fortification that are yet to implement them effectively and at scale [36]. The LMICs identified in our analysis have strong, already-established industrial milling infrastructures and high coverage and consumption of the respective grain, coupled with some of the world's heaviest nutritional burdens. Each of the countries of interest analyzed in the study is poised and ready to initiate and adopt large-scale grain fortification programs. This presents a unique opportunity to achieve marked reductions in the prevalence of anemia among WRA and folic acid-preventable NTDs, which are major contributors to individual growth and development, the burden of disease, healthcare costs, and barriers to economic productivity. This opportunity warrants an urgent call to action for stronger political support among government leaders, key stakeholders in each of these countries, and global and regional technical support bodies that more can and should be done now to save lives, improve quality of life, and increase economic productivity at a national and global scale through the adoption and maintenance of strong and sustained fortification programs. Strong, sustained fortification programs may give countries an opportunity to achieve at least nine of the 17 SDGs, namely, (1) no poverty, (2) zero hunger, (3) good health and well-being, (4) quality education, (5) gender 
equality, (8) decent work and economic growth, (10) reduced inequalities, (11) sustainable cities and communities, and (17) partnership for the goals.

Author Contributions: V.K. contributed to conceptualization, data curation, analysis, writingoriginal draft preparation, and writing - review and editing; M.C. contributed to conceptualization, data curation, analysis, writing — original draft preparation, and writing-review and editing; L.R. contributed to conceptualization, data curation, analysis, writing-original draft preparation, and writing-review and editing; A.T. contributed to conceptualization, data curation, analysis, and writing-original draft preparation; S.J. contributed to the economic analysis and corresponding write-up; D.W. contributed to the economic analysis and corresponding write-up; H.M. contributed to conceptualization, data curation, analysis, writing — original draft preparation, and writing-review and editing. All authors read and agreed to the published version of the manuscript.

Funding: This research received no external funding.

Informed Consent Statement: Not applicable.

Data Availability Statement: Multiple public and third party datasets were used. Publicly available datasets analyzed in this study can be found here: (a) World Health Organization. The Global Prevalence of Anaemia in 2011; World Health Organization: Geneva, Switzerland, 2015. World Health Organization. The Global Prevalence of Anaemia in 2011; World Health Organization: Geneva, Switzerland, 2015. Available online: https://www.who.int/nutrition/publications/micronutrients/global_ prevalence_anaemia_2011/en/. (b) Global Fortification Data Exchange (GFDx). Available online: https:/ / fortificationdata.org. (c) UNICEF. State of the World's Children 2019. Available online: https:/ / www.unicef.org/media/63016/file/SOWC-2019.pdf. (d) The Food Fortification Initiative. Country Profiles. Available online: https:/ / www.ffinetwork.org/country-profiles. (e) Global Burden of Disease Collaborative Network. Global Burden of Disease Study 2017 (GBD 2017) Disability Weights; Institute for Health Metrics and Evaluation (IHME): Seattle, WA, USA, 2018. Available online: http://ghdx.healthdata.org/record/ihme-data/gbd-2017-disability-weights. (f) World Health Organization. Global Health Observatory Data Repository; Prevalence of Anaemia in Women of Reproductive Age; WHO: Geneva, Switzerland, 2017. Available online: https:/ /apps.who.int/gho/ data/view.main.ANAEMIAWOMENPREVANEMIAREG?lang=en Viscusi, W.K.; Masterman, C.J. Income Elasticities and Global Values of a Statistical Life. J. Benef. Cost Anal. 2017. Available online: https:/ / static1.squarespace.com/static/5be33b0efcf7fdd77c7823be/t/5be9f13021c67c13124b3 a77/1542058289675/361_Income_Elasticity_of_Global_Values_of_a_Statistical_Life.pdf. (g) ICF, 2012. The DHS Program STATcompiler. Funded by USAID. Available online: http: / www.statcompiler. com. Restrictions apply to the availability of these data. Data was obtained from Blencowe et al., (2018) [3] and are available from the authors with the permission of Dr. Hannah Blencowe.

Acknowledgments: The authors thank the following individuals for their technical and conceptual expertise throughout all aspects of this study: Godfrey P. Oakley, Jr. (Emory University Rollins School of Public Health), Lieven Bauwens (International Federation for Spina Bifida and Hydrocephalus); Mandana Arabi (Nutrition International), Marinus Koning (Reach Another Foundation), Martine Austin (International Federation for Spina Bifida and Hydrocephalus), Renée Jopp (International Federation for Spina Bifida and Hydrocephalus), and Scott Montgomery (FFI).

Conflicts of Interest: The authors declare no conflict of interest.

\section{Appendix A}

Table A1. Estimated annual health impact and economic value of fortification at scale: 17 Indian states.

\begin{tabular}{ccccccc}
\hline Indian State & $\begin{array}{c}\text { People } \\
\text { Reached } \\
\text { (Millions) }\end{array}$ & $\begin{array}{c}\text { Cases of } \\
\text { Anemia in } \\
\text { WRA Averted }\end{array}$ & $\begin{array}{c}\text { Cases of NTDs } \\
\text { Averted }\end{array}$ & $\begin{array}{c}\text { Child Deaths } \\
\text { Averted }\end{array}$ & $\begin{array}{c}\text { DALYs } \\
\text { Averted }\end{array}$ & $\begin{array}{c}\text { Economic Value of } \\
\text { DALYs Averted } \\
\text { (in USD \$ m) }\end{array}$ \\
\hline Andhra Pradesh & 25.1 & $1,282,143$ & 943 & 874 & 100,154 & 260 \\
Assam & 16.4 & 639,396 & 816 & 757 & 72,946 & 172 \\
Bihar & 56.2 & $2,882,247$ & 2364 & 2193 & 240,692 & 612 \\
Chhattisgarh & 13.5 & 539,333 & 800 & 742 & 68,509 & 157 \\
Haryana & 13.2 & 702,042 & 617 & 572 & 61,084 & 153 \\
Himachal Pradesh & 3.5 & 158,175 & 117 & 108 & 12,472 & 33 \\
Jharkhand & 17.6 & 975,552 & 806 & 748 & 81,499 & 206 \\
Karnataka & 31.4 & $1,195,893$ & 1266 & 1174 & 120,029 & 293 \\
\hline
\end{tabular}


Table A1. Cont.

\begin{tabular}{|c|c|c|c|c|c|c|}
\hline Indian State & $\begin{array}{c}\text { People } \\
\text { Reached } \\
\text { (Millions) }\end{array}$ & $\begin{array}{c}\text { Cases of } \\
\text { Anemia in } \\
\text { WRA Averted }\end{array}$ & $\begin{array}{c}\text { Cases of NTDs } \\
\text { Averted }\end{array}$ & $\begin{array}{l}\text { Child Deaths } \\
\text { Averted }\end{array}$ & $\begin{array}{c}\text { DALYs } \\
\text { Averted }\end{array}$ & $\begin{array}{l}\text { Economic Value of } \\
\text { DALYs Averted } \\
\text { (in USD \$ m) }\end{array}$ \\
\hline Kerala & 16.8 & 490,413 & 580 & 538 & 54,086 & 131 \\
\hline Madhya Pradesh & 38.8 & $1,732,766$ & 1691 & 1569 & 163,140 & 403 \\
\hline Maharashtra & 57.4 & $2,341,889$ & 2084 & 1933 & 208,893 & 527 \\
\hline Orissa & 21.6 & 934,548 & 798 & 740 & 80,870 & 205 \\
\hline Punjab & 14.1 & 640,540 & 481 & 446 & 51,056 & 133 \\
\hline Rajasthan & 36.9 & $1,466,494$ & 1946 & 1805 & 171,827 & 401 \\
\hline Tamil Nadu & 36.4 & $1,701,949$ & 1093 & 1013 & 123,627 & 331 \\
\hline Uttar Pradesh & 107.8 & $4,800,876$ & 4085 & 3788 & 413,783 & 1049 \\
\hline West Bengal & 46.4 & $2,465,850$ & 1519 & 1409 & 173,436 & 466 \\
\hline TOTAL (17 states) & 553.1 & $24,950,107$ & 22,006 & 20,410 & $2,198,103$ & 5532 \\
\hline
\end{tabular}

Table A2. Sensitivity analysis: monetized DALYs at $0 \%, 3 \%$, and 5\% discount rates at a national level.

\begin{tabular}{cccc}
\hline & & Monetized DALYs (\$ Millions) \\
\cline { 2 - 4 } Country/Region & $\mathbf{0 \%}$ Discount Rate & 3\% Discount Rate & $\mathbf{5 \%}$ Discount Rate \\
\hline Angola & 676.75 & 383.2 & 303.4 \\
Bangladesh & 1042.42 & 593.7 & 486.3 \\
Benin & 91.26 & 63.5 & 56.1 \\
China & $29,863.50$ & $20,298.0$ & $18,150.7$ \\
Côte d'Ivoire & 110.28 & 93.4 & 88.6 \\
Egypt & 1284.55 & 699.3 & 559.0 \\
Ethiopia & 214.26 & 140.7 & 121.9 \\
Ghana & 214.88 & 146.7 & 128.7 \\
India (17 states) & 8669.83 & 531.5 & 4756.8 \\
Indonesia & 286.79 & 195.6 & 173.6 \\
Kazakhstan & 430.41 & 370.1 & 356.0 \\
Kyrgyzstan & 20.77 & 17.4 & 16.6 \\
Liberia & 8.68 & 5.6 & 4.8 \\
Morocco & 448.41 & 309.9 & 278.3 \\
Nigeria & 3220.71 & 2363.9 & 2112.4 \\
Philippines & 864.40 & 536.7 & 457.1 \\
Senegal & 79.11 & 64.1 & 60.3 \\
Tajikistan & 34.57 & 28.6 & 27.2 \\
Total & $\mathbf{4 7 . 6} \mathbf{B}$ & 31.8 B & $\mathbf{2 8 . 1} \mathbf{B}$ \\
\hline
\end{tabular}

Table A3. Sensitivity analysis: monetized DALYs at $0 \%, 3 \%$, and 5\% discount rates: 17 Indian states

\begin{tabular}{cccc}
\hline & & Monetized DALYs (\$ millions) & \\
\cline { 2 - 4 } Indian State & $\mathbf{0 \%}$ Discount Rate & 3\% Discount Rate & $\mathbf{5 \%}$ Discount Rate \\
\hline Andhra Pradesh & 394.76 & 260.3 & 227.2 \\
Assam & 288.1 & 171.7 & 142.9 \\
Bihar & 949.14 & 612 & 528.7 \\
Chhattisgarh & 270.73 & 156.7 & 128.6 \\
Haryana & 240.95 & 153 & 131.3 \\
Himachal Pradesh & 49.16 & 32.5 & 28.4 \\
Jharkhand & 321.41 & 206.4 & 178 \\
Karnataka & 473.71 & 293.2 & 248.6 \\
Kerala & 213.5 & 130.8 & 110.3 \\
Madhya Pradesh & 643.72 & 402.5 & 343 \\
Maharashtra & 823.89 & 526.6 & 453.2 \\
Orissa & 318.92 & 205.1 & 177 \\
Punjab & 201.24 & 132.7 & 115.7 \\
Rajasthan & 678.75 & 401.2 & 332.7 \\
Tamil Nadu & 486.96 & 331.1 & 292.6 \\
Uttar Pradesh & 1631.79 & 1049.20 & 413 \\
West Bengal & 683.09 & 466.5 & $\mathbf{4 . 8}$ \\
TOTAL & 8.7 B & 5.5 B \\
\hline
\end{tabular}


Table A4. Sensitivity analysis: cost-benefit ratio at $0 \%, 3 \%$, and $5 \%$ and $1 \times$ and $3 \times$ unit cost $(0.37$ USD) at a national level.

\begin{tabular}{|c|c|c|c|c|c|c|}
\hline \multirow{3}{*}{ Country/Region } & \multicolumn{6}{|c|}{ Benefit-Cost Ratio } \\
\hline & \multicolumn{2}{|c|}{ 0\% Discount Rate } & \multicolumn{2}{|c|}{ 3\% Discount Rate } & \multicolumn{2}{|c|}{ 5\% Discount Rate } \\
\hline & At $1 \times$ Unit Cost & At $3 \times$ Unit Cost & At $1 \times$ Unit Cost & At $3 \times$ Unit Cost & At $1 \times$ Unit Cost & At $3 \times$ Unit Cost \\
\hline Angola & 202.79 & 67.60 & 114.81 & 38.27 & 90.93 & 30.31 \\
\hline Bangladesh & 19.49 & 6.50 & 11.10 & 3.70 & 9.09 & 3.03 \\
\hline Benin & 24.04 & 8.01 & 16.74 & 5.58 & 14.78 & 4.93 \\
\hline China & 62.82 & 20.94 & 42.70 & 14.23 & 38.18 & 12.73 \\
\hline Côte d'Ivoire & 24.32 & 8.11 & 20.60 & 6.87 & 19.54 & 6.51 \\
\hline Egypt & 39.20 & 13.07 & 21.34 & 7.11 & 17.06 & 5.69 \\
\hline Ethiopia & 6.85 & 2.28 & 4.50 & 1.50 & 3.90 & 1.30 \\
\hline Ghana & 28.97 & 9.66 & 19.78 & 6.59 & 17.35 & 5.78 \\
\hline India (17 states) & 42.37 & 14.12 & 27.03 & 9.01 & 23.25 & 7.75 \\
\hline Indonesia & 31.67 & 10.56 & 21.61 & 7.20 & 19.17 & 6.39 \\
\hline Kazakhstan & 70.63 & 23.54 & 60.74 & 20.25 & 58.42 & 19.47 \\
\hline Kyrgyzstan & 9.90 & 3.30 & 8.32 & 2.77 & 7.93 & 2.64 \\
\hline Liberia & 8.43 & 2.81 & 5.46 & 1.82 & 4.68 & 1.56 \\
\hline Morocco & 37.40 & 12.47 & 25.85 & 8.62 & 23.22 & 7.74 \\
\hline Nigeria & 79.57 & 26.52 & 58.40 & 19.47 & 52.19 & 17.40 \\
\hline Philippines & 28.94 & 9.65 & 17.97 & 5.99 & 15.30 & 5.10 \\
\hline Senegal & 15.03 & 5.01 & 12.19 & 4.06 & 11.47 & 3.82 \\
\hline Tajikistan & 11.93 & 3.98 & 9.89 & 3.30 & 9.39 & 3.13 \\
\hline TOTAL & 51.40 & 17.13 & 34.41 & 11.47 & 30.41 & 10.14 \\
\hline MEDIAN & 28.96 & 9.65 & 20.19 & 6.73 & 17.20 & 5.73 \\
\hline RANGE & $6.9-202.8$ & $2.3-67.6$ & $4.5-114.8$ & $1.5-38.3$ & $3.9-90.9$ & $1.3-30.3$ \\
\hline
\end{tabular}

Table A5. Sensitivity analysis: cost-benefit ratio at $0 \%, 3 \%$, and $5 \%$ and $1 \times$ and $3 \times$ unit cost (0.37 USD): 17 Indian states.

\begin{tabular}{|c|c|c|c|c|c|c|}
\hline \multirow{3}{*}{ Country/Region } & \multicolumn{6}{|c|}{ Benefit-Cost Ratio } \\
\hline & \multicolumn{2}{|c|}{ 0\% Discount Rate } & \multicolumn{2}{|c|}{ 3\% Discount Rate } & \multicolumn{2}{|c|}{ 5\% Discount Rate } \\
\hline & At $1 \times$ Unit Cost & At $3 \times$ Unit Cost & At $1 \times$ Unit Cost & At $3 \times$ Unit Cost & At $1 \times$ Unit Cost & At $3 \times$ Unit Cost \\
\hline Andhra Pradesh & 42.44 & 14.15 & 27.99 & 9.33 & 24.42 & 8.14 \\
\hline Assam & 47.62 & 15.87 & 28.37 & 9.46 & 23.62 & 7.87 \\
\hline Bihar & 45.62 & 15.21 & 29.41 & 9.8 & 25.41 & 8.47 \\
\hline Chhattisgarh & 54.2 & 18.07 & 31.37 & 10.46 & 25.74 & 8.58 \\
\hline Haryana & 49.44 & 16.48 & 31.4 & 10.47 & 26.94 & 8.98 \\
\hline Himachal Pradesh & 38.2 & 12.73 & 25.27 & 8.42 & 22.08 & 7.36 \\
\hline Jharkhand & 49.35 & 16.45 & 31.69 & 10.56 & 27.33 & 9.11 \\
\hline Karnataka & 40.77 & 13.59 & 25.23 & 8.41 & 21.39 & 7.13 \\
\hline Kerala & 34.3 & 11.43 & 21.01 & 7 & 17.73 & 5.91 \\
\hline Madhya Pradesh & 44.81 & 14.94 & 28.02 & 9.34 & 23.87 & 7.96 \\
\hline Maharashtra & 38.79 & 12.93 & 24.8 & 8.27 & 21.34 & 7.11 \\
\hline Orissa & 39.98 & 13.33 & 25.72 & 8.57 & 22.19 & 7.4 \\
\hline Punjab & 38.61 & 12.87 & 25.45 & 8.48 & 22.2 & 7.4 \\
\hline Rajasthan & 49.76 & 16.59 & 29.41 & 9.8 & 24.39 & 8.13 \\
\hline Tamil Nadu & 36.15 & 12.05 & 24.58 & 8.19 & 21.73 & 7.24 \\
\hline Uttar Pradesh & 40.92 & 13.64 & 26.31 & 8.77 & 22.7 & 7.57 \\
\hline West Bengal & 39.77 & 13.26 & 27.16 & 9.05 & 24.05 & 8.02 \\
\hline TOTAL & 42.37 & 14.12 & 27.03 & 9.01 & 23.25 & 7.75 \\
\hline MEDIAN & 40.92 & 13.64 & 27.16 & 9.05 & 23.62 & 7.87 \\
\hline RANGE & $34.3-54.2$ & $11.4-18.1$ & $21-31.7$ & 7-10.6 & $17.7-27.3$ & $5.9-9.1$ \\
\hline
\end{tabular}

\section{References}

1. Petry, N.; Olofin, I.; Hurrell, R.F.; Boy, E.; Wirth, J.P.; Moursi, M.; Donahue Angel, M.; Rohner, F. The proportion of anemia associated with iron deficiency in low, medium, and high human development index countries: A systematic analysis of national surveys. Nutrients 2016, 8, 693. [CrossRef] [PubMed]

2. World Health Organization. The Global Prevalence of Anaemia in 2011; World Health Organization: Geneva, Switzerland, 2015. Available online: https://www.who.int/nutrition/publications/micronutrients/global_prevalence_anaemia_2011/en/ (accessed on 7 June 2020).

3. Blencowe, H.; Kancherla, V.; Moorthie, S.; Darlison, W.; Modell, B. Estimates of global and regional prevalence of neural tube defects for 2015: A systematic analysis. Ann. N. Y. Acad. Sci. 2018, 1414, 31-46. [CrossRef] [PubMed]

4. Botto, L.D.; Moore, C.A.; Khoury, M.J.; Erickson, J.D. Neural-tube defects. N. Engl. J. Med. 1999, 341, 509-519. [CrossRef] [PubMed] 
5. $\quad$ Crider, K.S.; Devine, O.; Hao, L.; Dowling, N.F.; Li, S.; Molloy, A.M.; Li, Z.; Zhu, J.; Berry, R.J. Population red blood cell folate concentrations for prevention of neural tube defects: Bayesian model. BMJ 2014, 349, g4554. [CrossRef] [PubMed]

6. Horton, S.; Alderman, H.; Rivera, J.A. Copenhagen Consensus 2008 Challenge Paper: Hunger and Malnutrition, Draft. Denmark: Copenhagen Consensus Center. Copenhagen Consensus Center, 2008. Available online: https:/ /www.copenhagenconsensus. com/sites/default/files/CP_Malnutrition_and_Hunger_-_Horton.pdf (accessed on 8 December 2020).

7. Keats, E.C.; Neufeld, L.; Garrett, G.S.; Mbuya, M.N.M.; Bhutta, Z.A. Improved micronutrient status and health outcomes in lowand middle-income countries following large-scale fortification: Evidence from a systematic review and meta-analysis. Am. J. Clin. Nutr. 2019, 10, 1093-1105. [CrossRef] [PubMed]

8. Allen, L.; de Benoist, B.; Dary, O.; Hurrel, R. (Eds.) Guidelines on Food Fortification with Micronutrients; World Health Organization; Food and Agriculture Organization: Geneva, Switzerland, 2006.

9. The Food Fortification Initiative. Flour Fortification with Iron, Folic Acid, Vitamin B12, Vitamin A, and Zinc: Proceedings of the Second Technical Workshop on Wheat Flour Fortification; The Food Fortification Initiative: Atlanta, GA, USA, 2018. Available online: https:/ / static1.squarespace.com/static/5e1df234eef02705f5446453/t/5f8dbd4dca01f45f6cc66113/1603124605613/FNB201 0.pdf (accessed on 14 January 2021).

10. Zimmerman, S.; Baldwin, R.; Codling, K.; Hindle, P.; Montgomery, S.; Pachon, H.; Maberly, G. Mandatory policy: Most successful way to maximize fortification's effect on vitamin and mineral deficiency. Indian J. Commun. Health 2014, 26, 369-374.

11. Atta, C.A.; Fiest, K.M.; Frolkis, A.D.; Jette, N.P.T.; St Germaine-Smith, C.; Rajapakse, T.; Kaplan, G.G.; Metcalfe, A. Global birth prevalence of spina bifida by folic acid fortification status: A systematic review and meta-analysis. Am. J. Public Health 2016, 106, e124-e134. [CrossRef]

12. Global Fortification Data Exchange (GFDx). Available online: https:/ / fortificationdata.org (accessed on 15 June 2020).

13. The Food Fortification Initiative: Fortify to Address Sustainable Development Goals. Available online: https://www.ffinetwork. org/world (accessed on 15 June 2020).

14. World Health Organization. Number of Countries Categorized by Public Health Significance of Anemia; World Health Organization: Geneva, Switzerland, 2008; Available online: https://www.who.int/vmnis/anaemia/prevalence/anaemia_data_status_t4/en/ (accessed on 7 December 2020).

15. World Health Organization: Recommendations on Wheat and Maize Flour Fortification. Available online: https://www.who.int/ nutrition/publications/micronutrients/wheat_maize_fort.pdf?ua=1 (accessed on 7 December 2020).

16. The Food Fortification Initiative. Country Profiles. Available online: https://www.ffinetwork.org/country-profiles (accessed on 15 June 2020).

17. World Health Organization. Maternal, Newborn, Child and Adolescent Health and Ageing; WHO: Geneva, Switzerland, 2019.

18. UNICEF. State of the World's Children 2019. Available online: https://www.unicef.org/media/63016/file/SOWC-2019.pdf (accessed on 7 December 2020).

19. Castillo-Lancellotti, C.; Tur, J.A.; Uauy, R. Impact of folic acid fortification of flour on neural tube defects: A systematic review. Public Health Nutr. 2013, 16, 901-911. [CrossRef] [PubMed]

20. Cortes, F.; Mellado, C.; Pardo, R.A.; Villarroel, L.A.; Hertrampf, E. Wheat flour fortification with folic acid: Changes in neural tube defects rates in Chile. Am. J. Med. Genet. A 2012, 158A, 1885-1890. [CrossRef] [PubMed]

21. De Wals, P.; Tairou, F.; Van Allen, M.I.; Uh, S.H.; Lowry, R.B.; Sibbald, B.; Evans, J.A.; Van den Hof, M.C.; Zimmer, P.; Crowley, M.; et al. Reduction in neural-tube defects after folic acid fortification in Canada. N. Engl. J. Med. 2007, 357, 135-142. [CrossRef] [PubMed]

22. Sayed, A.R.; Bourne, D.; Pattinson, R.; Nixon, J.; Henderson, B. Decline in the prevalence of neural tube defects following folic acid fortification and its cost-benefit in South Africa. Birth. Defects Res. A Clin. Mol. Teratol. 2008, 82, 211-216. [CrossRef] [PubMed]

23. Williams, L.J.; Mai, C.T.; Edmonds, L.D.; Shaw, G.M.; Kirby, R.S.; Hobbs, C.A.; Sever, L.E.; Miller, L.A.; Meaney, F.J.; Levitt, M. Prevalence of spina bifida and anencephaly during the transition to mandatory folic acid fortification in the United States. Teratology 2002, 66, S40-S43. [CrossRef] [PubMed]

24. Global Burden of Disease Collaborative Network. Global Burden of Disease Study 2017 (GBD 2017) Disability Weights; Institute for Health Metrics and Evaluation (IHME): Seattle, WA, USA, 2018. Available online: http://ghdx.healthdata.org/record/ihmedata/gbd-2017-disability-weights (accessed on 15 November 2020).

25. World Health Organization. Global Health Observatory Data Repository; Prevalence of Anaemia in Women of Reproductive Age; WHO: Geneva, Switzerland, 2017; Available online: https:/ / apps.who.int/gho/data/view.main.ANAEMIAWOMENPREVANEMIAREG? lang=en. (accessed on 15 November 2020).

26. ICF. The DHS Program STATcompiler. Funded by USAID. 2012. Available online: http://www.statcompiler.com (accessed on 15 November 2020).

27. Robinson, L.A.; Hammitt, J.K.; Cecchini, M.; Chalkidou, K.; Claxton, K.; Cropper, M.; Eozenou, P.H.; de Ferranti, D.; Deolalikar, A.N.; Guanais, F.; et al. Reference Case Guidelines for Benefit-Cost Analysis in Global Health and Development. Boston 2019. Available online: https:/ /cdn1.sph.harvard.edu/wp-content/uploads/sites/2447/2019/05/BCA-Guidelines-May2019.pdf (accessed on 7 December 2020). 
28. Bill and Melinda Gates Foundation and NICE International. Methods for Economic Evaluation Project (MEEP). In The Gates Reference Case. What It Is, Why It's Important, and How to Use It; National Institute for Clinical Excellence: Abingdon, UK, 2014.

29. Viscusi, W.K.; Masterman, C.J. Income Elasticities and Global Values of a Statistical Life. J. Benef. Cost Anal. 2017, 8, 226-250. Available online: https://static1.squarespace.com/static/5be33b0efcf7fdd77c7823be/t/5be9f13021c67c13124b3a77/15420582 89675/361_Income_Elasticity_of_Global_Values_of_a_Statistical_Life.pdf (accessed on 15 November 2020). [CrossRef]

30. Scott, N.; Delport, D.; Hainsworth, S.; Pearson, R.; Morgan, C.; Huang, S.; Akuoku, J.; Piwoz, E.; Shekar, M.; Levin, C.; et al. Ending malnutrition in all its forms requires scaling up proven nutrition interventions and much more: A 129-country analysis. BMC Med. 2020, 18, 356. [CrossRef] [PubMed]

31. Government of the Federal Democratic Republic of Ethiopia: Assessment of Feasibility and Potential Benefits of Food Fortification in Ethiopia. 2011. Available online: http:/ / citeseerx.ist.psu.edu/viewdoc / download?doi=10.1.1.659.5929\&rep=rep1\&type=pdf (accessed on 7 December 2020).

32. Berihu, B.A.; Welderufael, A.L.; Berhe, Y.; Magana, T.; Mulugeta, A.; Asfaw, S.; Gebreselassie, K. High burden of neural tube defects in Tigray, Northern Ethiopia: Hospital-based study. PLoS ONE 2018, 13, e0206212. [CrossRef] [PubMed]

33. Horton, S.; Shekar, M.; McDonald, C.; Mahal, A.; Brooks, J.K. Scaling Up Nutrition: What Will It Cost? Directions in Development Series; World Bank: Washington, DC, USA, 2010.

34. Shekar, M.; Kakietek, J.; Dayton Eberwein, J.; Walters, D. An Investment Framework for Nutrition: Reaching the Global Targets for Stunting, Anemia, Breastfeeding, and Wasting; The World Bank: Washington DC, USA, 2017.

35. Horton, S.; Mannar, V.; Wesley, A. Micronutrient Fortification (Iron and Salt Iodization) Edited by Copenhagen Consensus. 2008. Available online: https://www.copenhagenconsensus.com/sites/default/files/bpp_fortification.pdf (accessed on 7 December 2020).

36. Osendarp, S.J.M.; Martinez, H.; Garrett, G.S.; Neufeld, L.M.; De-Regil, L.M.; Vossenaar, M.; Darnton-Hill, I. Large-scale food fortification and biofortification in low- and middle-income countries: A review of programs, trends, challenges, and evidence gaps. Food Nutr. Bull. 2018, 39, 315-331. [CrossRef] [PubMed]

37. Martinez, H.; Weakland, A.P.; Bailey, L.B.; Botto, L.D.; De-Regil, L.M.; Brown, K. Improving maternal folate status to prevent infant neural tube defects: Working group conclusions and a framework for action. Ann. N. Y. Acad. Sci. 2018, 1414, 5-19. [CrossRef] [PubMed] 